\title{
STUDY OF AIR JET IMPINGING ON CURVED SURFACES
}

\author{
F.Sh. Abou-Taleb, A. Abdel-Fattah, and Gamal H. Moustafa \\ Department of Power Mechanical Engineering, Faculty of Engineering \\ Minoufiya University, Shebin El-Kom, Egypt \\ Email : fauzy1957@yahoo.com
}

\begin{abstract}
This study reports experimental and numerical results exposing the effect of the impingement surface geometry on the flow field for impinging low and high speed jets. Air jets from convergent circular nozzle of $10 \mathrm{~mm}$ exit diameter have been allowed to impinge normally on a flat plate, hemispherical, and conical surfaces. Experiments were done with varying the stagnation pressure from 1.2 to 2 bar. The Reynolds number based on the nozzle exit diameter for this range of stagnation pressure was changed from $7.5 \times 10^{5}$ to $3 \times 10^{6}$. The distance between the nozzle exit plane and the test surface was varied from 10 to $80 \mathrm{~cm}$. Measurements of static and total pressure were made by the help of pressure taps made on the test surfaces and a pitot tube. The numerical simulations were performed by the solution of Navier-Stokes equations with a $\mathrm{k}-\varepsilon$ model. Behaviors of the impinging jets were compared with those of a free jet. The flow field was found to be depend on the stagnation pressure, spacing between the nozzle and impinging surface, as well as the impinging surface geometry. A comparison of the predicted behavior of the jet with those obtained from experimental results gives a good agreement.

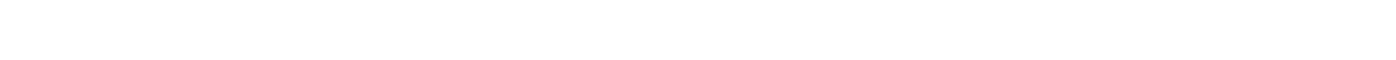

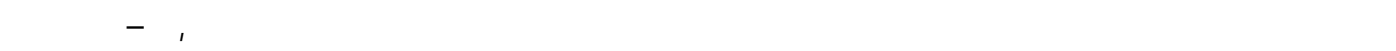

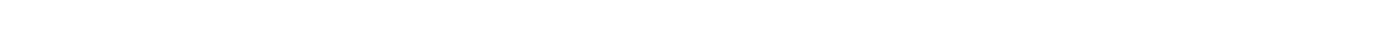

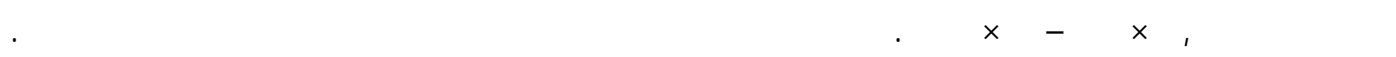

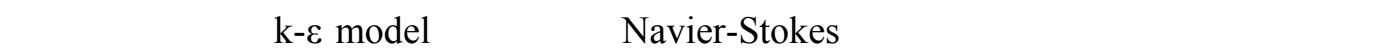

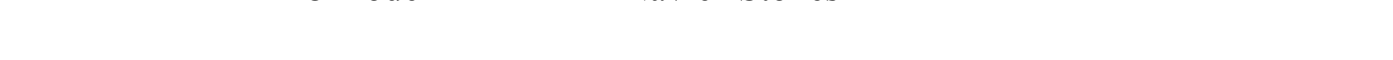

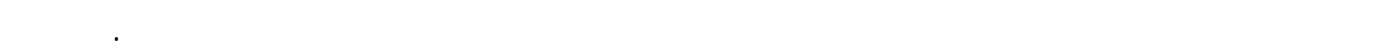

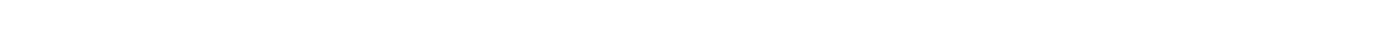

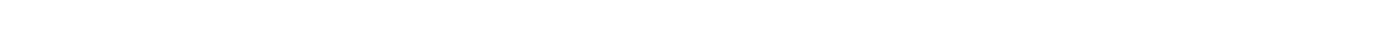

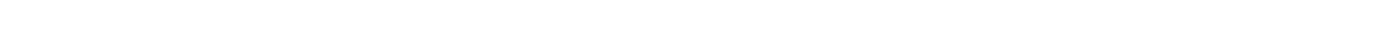

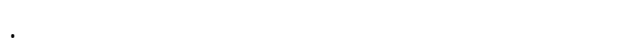

Keywords: jet, impingement surface, Navier Stokes, K- $\varepsilon$ model, Pitot tube

\section{NOMENCLATURE}

$\mathrm{c}_{1}, \mathrm{c}_{2}, \mathrm{c}_{3}, \mathrm{c}_{\mathrm{D}}, \sigma_{\mathrm{k}} \sigma_{\varepsilon}$ empirical constants in the turbulence model

d : nozzle exit diameter

D : Diameter, Fig. 1 b

$\mathrm{L}:$ Impingement distance

$\mathrm{k}$ : Turbulent Kinetic energy

$\mathrm{p}$ : pressure

$\mathrm{R}$ : gas constant

$\mathrm{S}_{\phi}:$ Source term

$\mathrm{T}$ : temperature

$\mathrm{V}_{\mathrm{o}}$ : mean velocity at nozzle exit

$\mathrm{u}, \mathrm{v}$ : velocity components along $\mathrm{r}, \mathrm{y}$

$\mathrm{r}, \mathrm{y}: \mathrm{r}$ and $\mathrm{y}$ directions

$\mathrm{L}$ : distance from the nozzle exit plane

Re : Reynolds number $\left(\rho \mathrm{V}_{\mathrm{o}} \mathrm{d} / \mu\right)$

$\rho$ : density

$\mu$ : Dynamic viscosity $\varepsilon:$ dissipation rate

$\Gamma_{\phi}:$ Diffusion coefficient

$\phi$ : general dependent variable

\section{Subscripts}

a : Ambient condition

o : Stagnation condition

w : wall condition

\section{INTRODUCTION}

A circular free jet is caused by the efflux of fluid in still air from circular nozzle or orifice. From the edges of the nozzle a free shear layer fans out. Close behind the nozzle exit the shear layer has zero width and increases with increasing distance from the nozzle exit plane. At a distance in the downstream direction equals the core length of the jet the shear layers coincide and cover the entire jet. The velocity at the axis stays constant up to this distance and then 
decreases with the distance. At the jet axis the flow is almost isotropic since there is no production of turbulence and the turbulence is only due to the transport by the mean and turbulent motion. Far enough behind the jet, behind the core length, the flow does not depend on the initial conditions.

When a surface is placed normal to the axis of a free jet, another structure of the flow field will occur. Such a jet is known as an impinging jet, which have many applications, such as the heat transfer in industrial equipment, flow field around VerticalTakeoff and Landing (VTOL) aircrafts. It is also used for the cooling, heating, and drying of paper, pulp, printer's ink, food, tissue, textiles, chemicals, film , and the cooling of hot steel plates, gas turbine cascade and combustor components. Recently, it is also used for cooling the microelectronic components. In fact, the wide use of such a jet is due to the enhancement of the high heat and mass transfer rates that occur in the impingement region. For (VTOL) aircrafts, an important consideration is the aerodynamic interaction between air frame under surfaces and the ground.

The main structure of the impinging jet is defined by three main regions, Hwang and Liu (1989)[10]. The first jet part is the free jet region where the flow is the same as that of a jet issuing into an unbounded medium. The second part is the impingement region in which the large pressure enhances the change of flow direction. The third part is the wall jet region where the flow moves over the ground plane with constant pressure.

Although many jet impingement studies have reported the effect of the impingement on flat surfaces, Lytle and Webb (1994)[17], Colucci and Viskanta (1996)[4], Phares, et. al. (2000)[21], and Kondaraju,and Lee (2006)[13]. However, a wide variety of components, including turbine blades, which can benefit from impingement cooling have a geometry which cannot be described in terms of a flat surface. For this reason, the effect of surface geometry on the impingement cooling processes warrants investigation. Yet few works on jet impingement on curved surfaces have been published, Hrycak ( 1981)[[9] studied the heat transfer from concave semi-cylinderical surfaces with the range of Reynolds number from $1.2 \times 10^{4}$ to $8.8 \times$ $10^{4}$. Lee and Lee (1997)[15] investigated the effect of surface curvature on the local heat transfer from a round jet. Earlier, Chupp, et. al. (1969)[3], studied the heat transfer from an array of small round jets impinging on a concave surface. Tabakoff and Clevenger ( 1972)[22] compared the cooling of a single slot jet with an array of round jets impinging on a concave surface. Impingement surfaces of more complex geometries such as cylindrical surfaces were investigated by Parneix, et. al. (1999)[18] and
Cornaro, et. al. (1999)[5]. Heat transfer for a pair of rectangular jets impinging upon inclined surface was studied by Patel and Roy, (2002)[20]. Flow field analysis of jet impinging on an inclined flat plate at high angles was investigated by Ito,et al.(2006)[11].

It is well known that the flow structure of an impinging jet produced by an orifice or a nozzle is very complex, due to the generation of vortices, ambient entrainment, separation, and interaction with impingement and/or confining walls. After the impingement the flow develops as a wall jet until it interacts with a confining wall. Hence, there are a number of parameters to be considered in the design of such systems: the distance between the nozzle and impingement surfaces, the flow rate, the initial flow conditions, the initial turbulence level and the overall geometry of the system. Gardon and Akfirat (1965)[7] investigated the effect of turbulence on the heat transfer augmentation by controlling free stream turbulence at the nozzle exit. Tam and Norum (1992)[23] studied the impingement tones of large aspect ratio subsonic rectangular jets. Lytle and Webb (1994)[17] measured flow structures and local heat transfer rates at the value of nozzle to plate spacing less than one nozzle diameter and found peculiar behavior not evident at higher impingement distances. Lee et. al. (1994)[16] compared the local heat transfer characteristics of an elliptic impingement jet with an orifice nozzle having an aspect ratio of 2.14. Chen, et. al. (2000)[1] studied the high Schmidt mass transfer in a laminar impinging slot jet flow for the Reynolds number from 220 to 690. An investigation of the flow structure of tone producing from supersonic impinging jets was reported by Henderson et. al., (2002)[8]. Numerical correlation of heat transfer from an array of hot air jets impinging on a concave surface was given by Fregeau, et.al. (2003)[6]. A comparison of tone noise from supersonic jet impinging on flat plat was discussed by Lah (2005)[14].

The objective of the present work is to provide insight into the jet vortex structure during impingement on curved surfaces with high relative curvature. The stagnation pressure was varied to change the initial flow Reynolds number from $7.5 \mathrm{x}$ $10^{5}$ to $3 \times 10^{6}$. Measurements of the wall and total pressures were made in the $\mathrm{r}$ and $\mathrm{y}$ directions. The distance between the nozzle exit and the impingement surfaces was varied from 10 to 80 nozzle diameter. Navier - Stokes equations with k- $\varepsilon$ model were used to perform the structure of flow field. Numerical work based on the SIMPLE procedure outlined by Patankar (1970)[19] was utilized. A comparison between the theoretical and experimental results is given. 


\section{EXPERIMENTAL SET UP AND PROCEDURE}

The schematic diagram of the experimental set up is given in Fig.1a. A high pressure blow down air supply system was used to produce the jet. Compressed dry air was discharged from two air compressors to an air tank of $8.3 \mathrm{~m}^{3}$. The maximum pressure in the air tank was automatically controlled to within 8 bar. Then, the compressed air was passed through a 3 " diameter pipeline to restored in a settling chamber whose dimensions are $1.75 \mathrm{~m}$ long and $0.8 \mathrm{~m}$ in diameter. The pipeline control section includes a gate valve followed by a pressure regulating valve. Two mesh wire screens were fixed in the settling chamber to reduce the air disturbances and make the flow uniform at the nozzle exit. A circular convergent nozzle made of Aluminum with $35 \mathrm{~mm}$ length, $30 \mathrm{~mm}$ inlet diameter, and $10 \mathrm{~mm}$ diameter at exit was attached to the settling chamber which was kept parallel to the ground floor. The air was accelerated through the nozzle and then released into the ambient atmosphere in the form of a free jet. The air jet was allowed to impinge on test surfaces. The test models were chosen as a circular flat plate having diameter of $600 \mathrm{~mm}$ made of Perspex, hemispherical surfaces with diameters of $53 \mathrm{~mm}$ and $113 \mathrm{~mm}$ made of PVC and conical surfaces of diameters of $58 \mathrm{~mm}$ and $80 \mathrm{~mm}$ and height of 300 $\mathrm{mm}$, made of PVC, Fig.1b. The impingement surface was placed normal to the flow direction.

Measurements of wall and total pressures were made at different values of stagnation pressure, from 1.2 to 2 bar. The corresponding Reynolds number based on the nozzle exit diameter was ranged from $7.5 \times 10^{5}$ to $3 \times 10^{6}$. The wall pressure was measured through tabs of $0.5 \mathrm{~mm}$ inner diameter made along the impingement surfaces. The uncertainty in tap locations in all direction was $\pm 0.4 \%$. The total pressure was measured by a pitot tube with an inner diameter of $0.5 \mathrm{~mm}$. The pitot tube was positioned on a three dimensional traversing mechanism with a pitch of $1 \mathrm{~mm}$ in all directions. The spatial resolution of the traverse system is $0.25 \mathrm{~mm}$ in all directions which is approximately $2.5 \%$ of its diameter. Water and Mercury U-tube manometers were connected to the pitot tube and pressure tabs that can help for pressure readings with an accuracy of $\pm 0.65 \%$. The stagnation pressure in the settling chamber was measured using a digital manometer, with uncertainty of $\pm 0.36 \%$. The distance between the surface and nozzle exit (the impingement distance, $\mathrm{L} / \mathrm{d}$ ) was varied from 10 to 80 with uncertainty of $2 \%$. The stagnation temperature in the settling chamber was measured using a digital thermometer whereas; a mercury thermometer was used to measure the ambient temperature. The temperature reading was uniform with an accuracy of $\pm 0.5{ }^{\circ} \mathrm{C}$. The ambient atmospheric pressure was measured using a barometer with an accuracy of about $\pm 0.25 \%$. The nearest walls were kept sufficiently far from the tunnel to exclude their effects.

\section{MATHEMATICAL MODELS}

The transport equations representing the conservation of mass, momentum, turbulent kinetic energy and turbulent dissipation rate of the isothermal flow are cast into a general form of axisymmertic cylindrical co-ordinates:

$$
\frac{1}{\mathrm{r}}\left[\frac{\partial}{\partial \mathrm{\partial}}(\rho \mathrm{ur} \phi)+\frac{\partial}{\partial \mathrm{y}}(\rho \mathrm{v} r \phi)\right]=-\frac{1}{\mathrm{r}}\left(\frac{\partial}{\partial \mathrm{r}}\left(\mathrm{r} \Gamma_{\phi} \frac{\partial \phi}{\partial \mathrm{x}}\right)+\frac{\partial}{\partial y}\left(\mathrm{r} \Gamma_{\phi} \frac{\partial \phi}{\partial \mathrm{y}}\right)\right\}+\mathrm{S}_{\phi}(\mathrm{r}, \mathrm{y})
$$

where $\phi$ represents one of the following entities $1, u$, $\mathrm{v}, \mathrm{k}$, and $\varepsilon$ in which the dependent variables are: $\mathrm{r}$ direction velocity $\mathrm{u}, \mathrm{y}$-direction velocity $\mathrm{v}$, turbulent kinetic energy $\mathrm{k}$ and its dissipation rate $\varepsilon . \Gamma_{\phi}$ and $\mathrm{S}_{\phi}$ stand for the corresponding effective diffusivity and source term, respectively. The corresponding expressions of $\Gamma_{\phi}$ and $S_{\phi}$ are given in Table 1, Khodadadi and Vlachos (1989)[12].

Table 1 Continuity, r-momentum, y-momentum, turbulent kinetic energy, and energy dissipation rate equations

\begin{tabular}{|c|c|l|c|}
\hline$\phi$ & $\Gamma_{\phi}$ & $\mathbf{S}_{\phi}$ & Remark \\
\hline $\mathbf{1}$ & 0 & 0 & Continuity \\
\hline $\mathbf{v}$ & $\mu_{\mathrm{eff}}$ & $-\frac{\partial \mathrm{P}}{\partial \mathrm{r}}+\frac{1}{\mathrm{r}} \frac{\partial}{\partial \mathrm{r}}\left(\mu_{\mathrm{eff}} \mathrm{r} \frac{\partial \mathrm{u}}{\partial \mathrm{r}}\right)+\frac{\partial}{\partial \mathrm{y}}\left(\mu_{\mathrm{eff}} \frac{\partial \mathrm{v}}{\partial \mathrm{r}}\right) \mu_{\mathrm{eff}} \frac{\mathrm{u}}{\mathrm{r}^{2}}-\frac{2}{3} \frac{\partial}{\partial \mathrm{r}}\left(\mu_{\mathrm{eff}}(\nabla \cdot \overline{\mathrm{V}})+\rho \mathrm{k}\right)$ & $\begin{array}{c}\text { Momentum in } \\
\text { axial direction }\end{array}$ \\
\hline $\mathbf{U}$ & $\mu_{\mathrm{eff}}$ & $-\frac{\partial P}{\partial y}+\frac{1}{r} \frac{\partial}{\partial r}\left(\mu_{\text {eff }} r \frac{\partial u}{\partial y}\right)+\frac{\partial}{\partial y}\left(\mu_{e f f} \frac{\partial v}{\partial y}\right)-\frac{2}{3} \frac{\partial}{\partial y}\left(\mu_{e f f}(\nabla \cdot \bar{V})+\rho k\right)$ & $\begin{array}{c}\text { Momentum in } \\
\text { radial direction }\end{array}$ \\
\hline $\mathbf{K}$ & $\frac{\mu_{\mathrm{eff}}}{\sigma_{\mathrm{k}}}$ & $\mathrm{G}_{\mathrm{k}}-\rho \varepsilon$ & $\begin{array}{c}\text { Turbulence } \\
\text { kinetic energy }\end{array}$ \\
\hline$\varepsilon$ & $\frac{\mu_{\mathrm{eff}}}{\sigma_{\varepsilon}}$ & $\frac{\varepsilon}{k}\left[c_{1} G-c_{2} \rho \varepsilon\right]+\left(1-c_{3}\right) \rho \varepsilon(\nabla \cdot \bar{V})$ & $\begin{array}{c}\text { Energy } \\
\text { dissipation rate } \\
\end{array}$ \\
\hline
\end{tabular}


where

$$
\begin{aligned}
G_{k}=\mu_{\text {eff }}\left\{2 \left[\left(\frac{\partial u}{\partial r}\right)^{2}\right.\right. & \left.\left.+\left(\frac{\partial v}{\partial y}\right)^{2}\left(\frac{u}{r}\right)^{2}\right]+\left(\frac{\partial u}{\partial y}+\frac{\partial v}{\partial r}\right)^{2}\right\} \\
& -\frac{2}{3}(\nabla \cdot \bar{V})\left[\mu_{\text {eff }}(\nabla \cdot \bar{V})+\rho k\right]
\end{aligned}
$$

and

$$
\mu_{\text {eff }}=c_{D} \frac{\rho k^{2}}{\varepsilon}+\mu \quad \rho=\frac{p}{R T}
$$

The turbulent constants are given as, Khodadadi and Vlachos (1989)[12] :

$\mathrm{c}_{1}=1.44, \mathrm{c}_{2}=1.92, \mathrm{c}_{3}=1.373, \mathrm{c}_{\mathrm{D}}=0.09, \sigma_{\mathrm{k}}=1$, $\sigma_{\varepsilon}=1.3$

\subsection{Boundary Conditions and Solution Procedure}

The flow at the nozzle exit was assumed to be fully developed; i.e., the axial gradients of all variables were set to zero. Thus, the boundary conditions were cast as follows, Fig.2 .

a) Inlet boundary $(\mathrm{a}-\mathrm{e})$

$$
v=V_{o}, k_{o}=0.04 V_{o}^{2}, \varepsilon_{o}=\frac{c_{D} k_{o}^{1.5}}{0.1 d}
$$

b) At outlet $(\mathrm{c}-\mathrm{d})$

$$
\frac{\partial \phi}{\partial r}=0, \text { and } \phi=u, v, k . \text { and.. } \varepsilon
$$

c) Symmetry axis $(\mathrm{a}-\mathrm{b})$

Here the radial velocity derivatives for all mean variables except the radial velocity are set to zero also and are to zero at the symmetry axis .i-e $\mathrm{u}=0$ and $\frac{\partial \phi}{\partial r}=0 .$. and .. $\phi=v, k$..and.. $\varepsilon$

d) At solid wall (b - c)

At solid walls, there is no slip and the law of the wall suggested by Chiu and Kuo (1995)[2] was used to modify the flow parameters, i.e.,u, v, and $\varepsilon$.

The mathematical models consist of a set of differential equations subjected to appropriate boundary conditions. To provide the algebraic form of the governing equations, a fully staggered grid system was adopted for the velocity components and scalar variables. These equations were discretized using a control volume finite difference methods (CVFDM). The numerical solution was accomplished by utilizing a version of Semi-Implicit Method for Pressure Linked Equation model (SIMPLE) derived by Patanker (1970). In this algorithm, the velocity component $\mathrm{u}$ was calculated at the east and west faces of the main control volumes from the solution of $u$ momentum equations, Fig.2. Similarly, the velocity component $\mathrm{v}$ were obtained at the north and south faces of the main control volume. Then, the pressure correction equation was solved, and velocity and pressure fields were corrected. To complete the iteration, the turbulent kinetic energy and energy dissipation rate equations were solved successively. The discretization equations were solved by the line-by line procedure, which is a combination of Gauss Seidel and the tridiagonal matrix algorithm in the stream-wise direction. The tridiagonal matrix algorithm (TDMA) was used to solve a set of discretization equations in the cross stream direction. Relaxation factors were employed to promote smooth convergence of the discretized equations. The relaxation factors were $0.5,0.5,0.3,0.8$, and 0.8 for $\mathrm{u}, \mathrm{v}, \mathrm{p}, \mathrm{k}$, and $\varepsilon$ respectively. The turbulent viscosity was under-relaxed at a value of 0.8 . The converged criterion in this study was based on the successive changes in variables. All field variables were monitored, and the following condition was used to declare the convergence:

$$
\operatorname{Max}\left|\frac{\phi_{i, j}^{n}-\phi_{i, j}^{n-1}}{\phi_{i, j}^{n}}\right| \leq 1 \times 10^{-4}
$$

In addition, the ratio of the difference between the inlet mass flow rate and the outlet mass flow rate to the inlet mass flow rate was also examined. Convergence was declared if the relative mass imbalance was less than $1 \times 10^{-3}$ and the Eq. (2) was satisfied simultaneously. To verify the algorithm, numerical tests were performed. Thus, 90 x 90 grids were placed non-uniformly in the computational domain. The r-direction (stream-wise) grid was fine under the jet, and the grid size was multiplied by a factor of 1.04 for the region between the jet and the downstream domain. The y-direction grid was chosen non-uniform, where the finest grids were set near the solid wall and expanded outward by power low formulation with a factor of 1.06 .

\section{RESULTS AND DISCUSSION}

The features of the impinging jet was studied experimentally and numerically for different flow and geometrical conditions. Sample of data are presented as pressure distributions and contours of $\mathrm{u}$, $\mathrm{v}$, and $\mathrm{k}$. The total pressure distributions in the distance between the impingement surface and nozzle is given in Fig. 3, for the case of flat plate, hemispherical, and conical surfaces. The space between the nozzle and impingement surface is kept constant, $\mathrm{L} / \mathrm{D}=25$. These data give a good indication about the general structure of the jet which means that the jet mean structure is independent on the impingement wall geometry, for upstream. In Fig.4, the wall pressure distributions for a jet impinging on a flat plate is given for comparison with the other impingement surfaces. At the center, the wall pressure is maximum. As the jet moves along the wall the static pressure decreases and then equals the ambient pressure. Fig.5 indicates the effect of stagnation pressure on the wall pressure distribution 
along the flat plate. The increase in the stagnation pressure increases the wall pressure every where along the surface.

The wall pressure distributions for the case of the hemispherical surface $(\mathrm{D} / \mathrm{d}=5.3)$ is given in Fig. 6, for different downstream locations. At the center of the surface, the wall pressure is maximum and has a tophat profile. It decreases as the flow moves along the surface in the $\mathrm{x}$-direction. The spreading of the jet (jet width) increases as the jet propagates, indicating the higher mixing rate with the ambient fluid. At $2 \leq$ $\mathrm{r} / \mathrm{d} \leq 4$, the wall pressure is negative and increases once again as the jet propagates along the surface. At the end of the impingement, the wall pressure equals the ambient pressure. Also, at the center of the hemispherical surfaces, the maximum pressure decreases with the increase of the distance between the jet exit plane and the surface. For the case of the hemispherical surfaces of $\mathrm{D} / \mathrm{d}=11.3$ the same behavior is evident. In this case, the negative pressure is shown at $3 \leq \mathrm{r} / \mathrm{d} \leq 6$, Fig.6c. The effect of stagnation pressure on the wall pressure is given in Fig.7. The general behavior is the same as that for the flat plate. At the center of the surface, the wall pressure is maximum and decreases as the jet moves along the surface. The maximum wall pressure decreases with the decrease of the stagnation pressure. Also, the negative pressure increases with the increase of the stagnation pressure. It is also higher for the case of the surface of $\mathrm{D} / \mathrm{d}=11.3$ than that for the case of $\mathrm{D} / \mathrm{d}=5.3$.

Fig. 8 shows the wall pressure distributions for the case of the conical surface $(\mathrm{D} / \mathrm{d}=5.3$ and 8$)$, for different downstream locations. The similar behavior of the wall pressure is performed. The maximum is shown at the center and the negative pressure is evident between $\mathrm{r} / \mathrm{d}=1$ and 2 , for $\mathrm{D} / \mathrm{d}=5.3$ and between $\mathrm{r} / \mathrm{d}=1$ and 3 for $\mathrm{D} / \mathrm{d}=8$. The effect of stagnation on the wall pressure is given in Fig.9.

In Fig. 10, the comparison between the test surfaces at $\mathrm{p}_{\mathrm{o}} / \mathrm{p}_{\mathrm{a}}=1.217$ and $\mathrm{L} / \mathrm{d}=30$. The same behavior is performed for all cases. The maximum wall pressure as well as the negative pressure are effected by the change of the impingement surface. The maximum and the higher negative pressures are shown with the case of the hemispherical surface.

Fig. 11 shows the comparison between the theoretical and experimental results for different values of stagnation pressure. The agreement between them is good. Both the experimental and theoretical results show that the peak values of wall pressure occur at the center and the pressure that to be lower than the ambient pressure occurs at the periphery of the jet. The pressure profile symmetry is excellent. The peak of the static pressure at the center of the plate increases with increasing the stagnation pressure. The agreement between the theoretical and experimental results is evident for all test surface. Also, the negative pressure is shown at the jet periphery. The contours of the velocities $\mathrm{u}, \mathrm{v}$ and kinetic energy $\mathrm{k}$ are given in Fig. 12. These results indicate that the numerical solution has reproduced the expected physical features of the jet interaction with the solid wall. The stagnation point, re-circulation zone, reflection, entrainment are clearly visible. The physical features of the jet change as the test surface geometry is changed.

\section{CONCLUSIONS}

An experimental investigation of an air circular jet impinging on different surfaces was undertaken. The results were compared with those obtain from the solution of the Navier-Stokes equations with a k- $\varepsilon$ model. The effect of the impingement surface geometry on the flow structure was performed. The impingement surfaces were chosen as a flat plate, hemispherical, and conical surfaces. The jet behavior in the form of total and wall pressure distributions was investigated by varying the nozzle to plate spacing, stagnation pressure ratio and the geometry of the impingement surface. These measurements were intended to gain understanding the pressure profile through the region between the nozzle and/over the impingement surface, since the changing of the surface geometry affects the structure of the impinging jets. Results also reveal that the general pressure profile is practically independent of the impingement surface, but is dependent on stagnation pressure and nozzle to surface spacing. The wall pressure is a maximum at stagnation point and decreases with increasing the distance along the surface. As the stagnation pressure increases, the maximum pressure increases every where. The pressure distribution shows a small region of lower pressure near the jet periphery, where the static pressure in that region is slightly smaller than the ambient pressure. The pressure recovery is inevitable since the momentum must be conserved. The computed results were shown to accurately predict the flow jet behavior over the surface. Complex features like separation and reattachment on the surface strongly influence the wall pressure distributions. Additionally, experimental and numerical results are in reasonable agreement.

\section{REFERENCES}

[1] Chen, M., Chalupa, R., West, A.C., and Modi, V., "High Schmidt Mass Transfer in a Laminar Impinging Slot jet Flow", Int. J. of Heat and Mass Transfer, Vol. 43, 2000, PP. 3907-3915.

[2] Chiu, C.P., and Kuo, Y.S., "Numerical Study of 'Turbulent Heat Transfer in a Motorized Engine Utilizing a Two Boundary Method Grid 
Generation Technique", Numerical Heat Transfer, Part A, Vol. 28, 1995, PP. 215-230.

[3] Chupp, R., Helms, H., McFadden, P., and Brown, T., "Evaluation of Internal Heat Transfer Coefficients for Impingement Cooled Turbine Airfoil”, J. Aircraft, Vol. 6, 1969, PP. 203-208.

[4] Colucci, D.W., and Viskanta, R. "Effect of Nozzle Geometry on Local Convective Heat Transfer to a Confined Impinging Air Jet", Experimental Thermal and Fluid Science, Vol. 13, 1996, pp. 71-80.

[5] Cornaro, C., Fleischer, A.S., and Goldstein, R.J., "Flow Visualization of a Round Jet Impinging on Cylindrical Surface", Experimental Thermal and Fluid Science, Vol. 20, 1999, pp. 66-78.

[6] Fregeau,M.,Saeed, F., and Paraschivoiu, I., " Numerical correlation of heat transfer from an array of hot air jets impinging on $3 \mathrm{D}$ concave Surface ", AIAA Journal , 2003,p.3403.

[7] Gardon, R., and Akfirat, J.C., "The Role of Turbulence in determining the heat transfer characteristics of impinging jets", Int. J. Heat Mass Transfer, vol. 8, 1965, PP. 1261- 1272.

[8] Henderson ,B., Brideges,J. and Wernet,M., "An Investigation of the Flow Structure of Tone Producing from Supersonic Impinging Jets", AIAA Journal, 2002,p.2529.

[9] Hrycak,P.,"Heat Transfer From a Row of Jets Impinging on Concave Semi-Cylindrical Surfaces", Int.J. Heat Mass Transfer,Vol.28,1981,pp. 175-181.

[10] Hwang, C.J.,and Liu,J.L., "Numerical Study of Two Dimensional Impinging Jet Flow Field", AIAA Journal,Vol.27,No.7,July 1989, pp. 841842.

[11] Ito, M, Oyama, A., Fujii, K., and Hayashi, "Flow Field Analysis of Jet Impinging on an Inclined Flat Plate Angles", AIAA Jornal,2006,P.1047.

[12] Khodadadi, J.M. and Vlachos, N.S., "Study of Coaxial Turbulent Jets", AIAA Journal, May (1989), pp.532-541.

[13] Kondaraju,S.,and Lee,J.S.," Behavior of Fluid Structure for the Impinging on a Flat Plate", AIAA Journal,2006,pp.1282.
[14] Lah,C.Y.,"Computational of Tone Noise from Supersonic Jet Impinging on Flat plate", AIAA Journal ,2005,pp.418.

[15] Lee, J., and Lee, S., "Turbulent Flow and Heat Transfer Measurements on a Curved Surface with a fully developed Round Impinging Jet", Int. J. of Heat and Fluid Flow, vol. 18, 1997, pp. 160-169.

[16] Lee, S.J.,Lee,J.,and Lee, D., "Local Heat Transfer Measurements From an Elliptic Jet Impinging on a Flat Plate Using Liquid Crystal", Int. J. Heat Mass Transfer, Vol. 37, 1994, pp. 967-976.

[17] Lytle, D., and Webb, B.W., "Jet Impingement Heat Transfer at Low Nozzle Plate Spacing", Int. J. Heat Mass Transfer, Vol. 37, 1994, pp. 16871697.

[18] Parneix,S., Behnia, M., and Durbin, P.A., "Predictions of Turbulent Heat Transfer in an Axisymmetric Jet Impinging on a Heated Pedestal", Journal of Heat Transfer, vol. 121, Feb. 1999, pp. 43-49.

[19] Patankar, S.V., "Numerical Heat Transfer and Fluid Flow", McGraw-Hill, New York, 1970.

[20] Patel,P., and Roy,S., "Heat Transfer for a Pair of Rectangular Jets Impinging Upon an Inclined Surface ",AIAA Journal ,2002,pp.210.

[21] Phares, D.J., Smedley, G.T., Flagan, R.C., "The Wall Shear Stress Produced by the Normal Impingement of a Jet on a Flat Surface", J. Fluid Mech., Vol. 418, 2000, pp. 351-375.

[22] Tabakoff, W., and Clevenger, W., "Gas Turbine Blade Heat Transfer Augmentation by Impingement of Air Jets Having various Configurations", J. Eng. Power, Vol. 94, 1972, pp. 51- 60 .

[23] Tam, C.K.W., and Norum, D., "Impingement Tones of Large Aspect Ratio Subsonic Rectangular Jets", AIAA Journal, Vol. 30, 1992, pp. 304-311. 


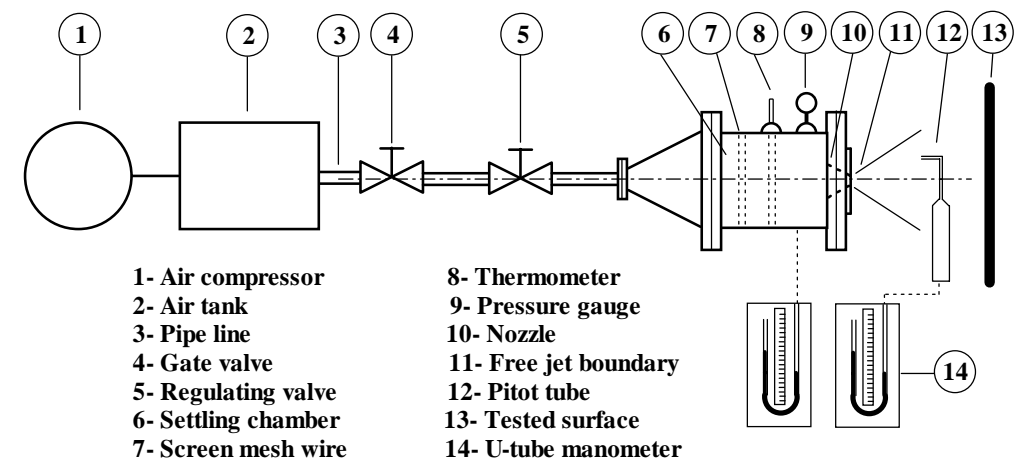

Fig. 1a Experimental setup.

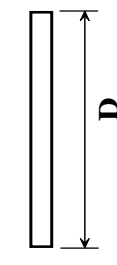

$\mathbf{D}=\mathbf{6 0 0} \mathbf{~ m m}$

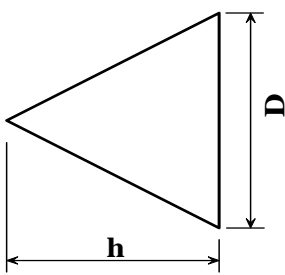

D $=58 \& 80 \mathrm{~mm}$ h $=300 \mathrm{~mm}$

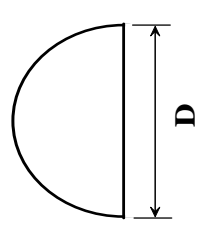

$\mathrm{D}=53 \& 113 \mathrm{~mm}$

Fig. 1b Test models.

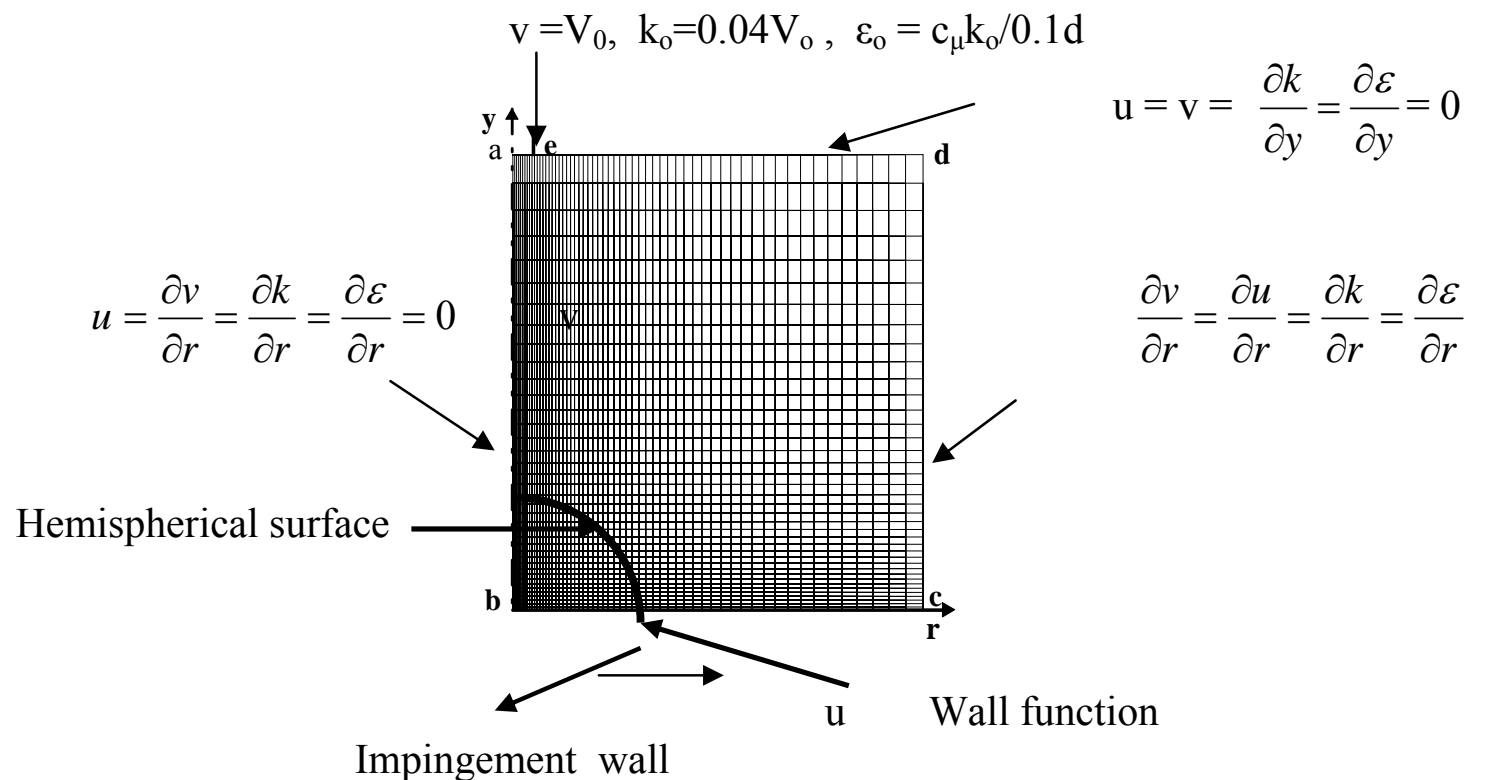

Fig. 2 Boundary conditions for computation 

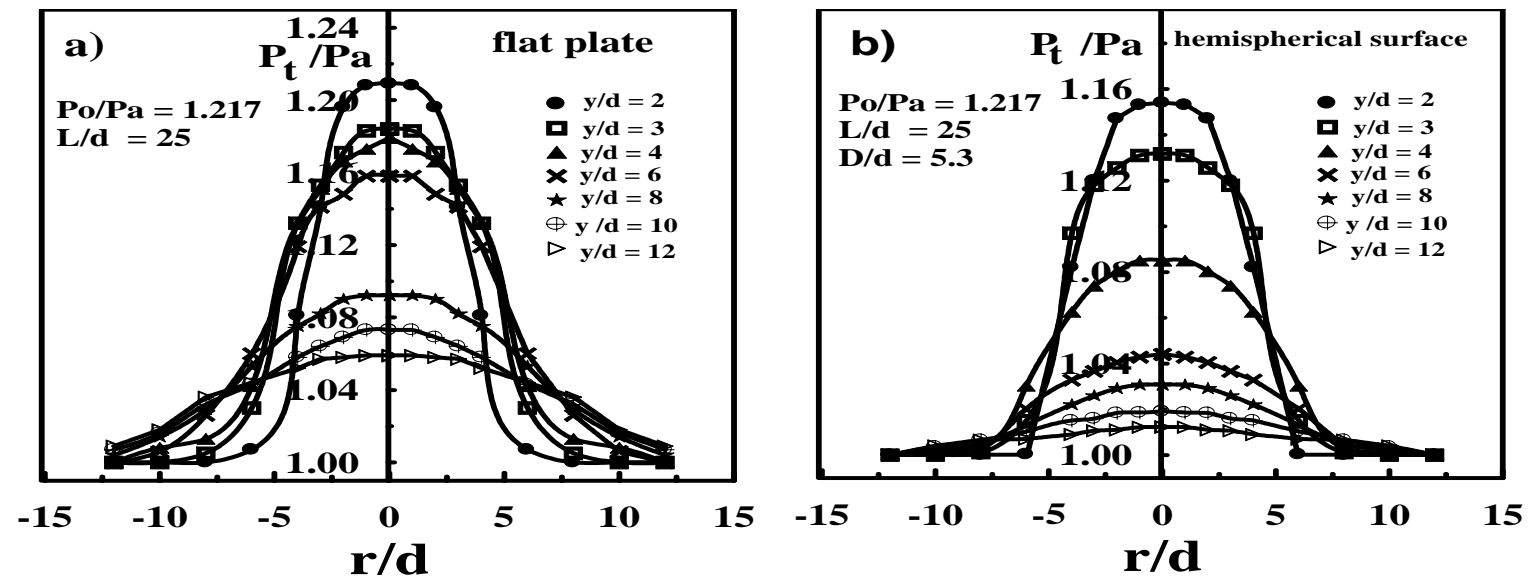

Fig. 3 Total pressure distribution in the space between the nozzle and wall
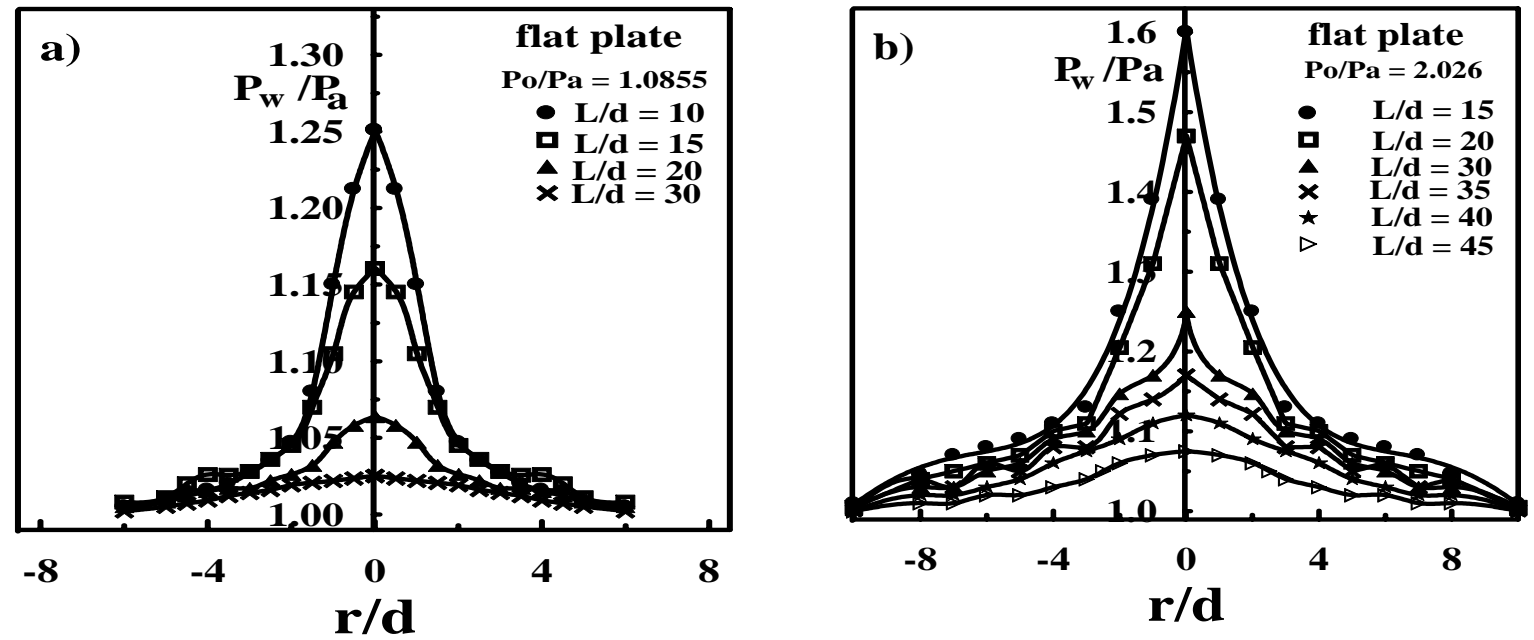

Fig. 4 Wall pressure distribution along a flat plate

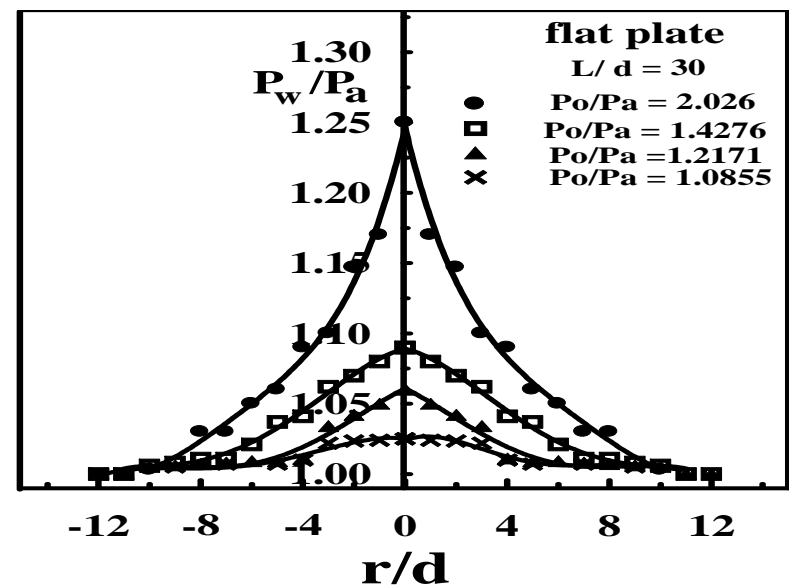

Fig. 5 Effect of stagnation pressure on Wall pressure distribution along a flat plate 

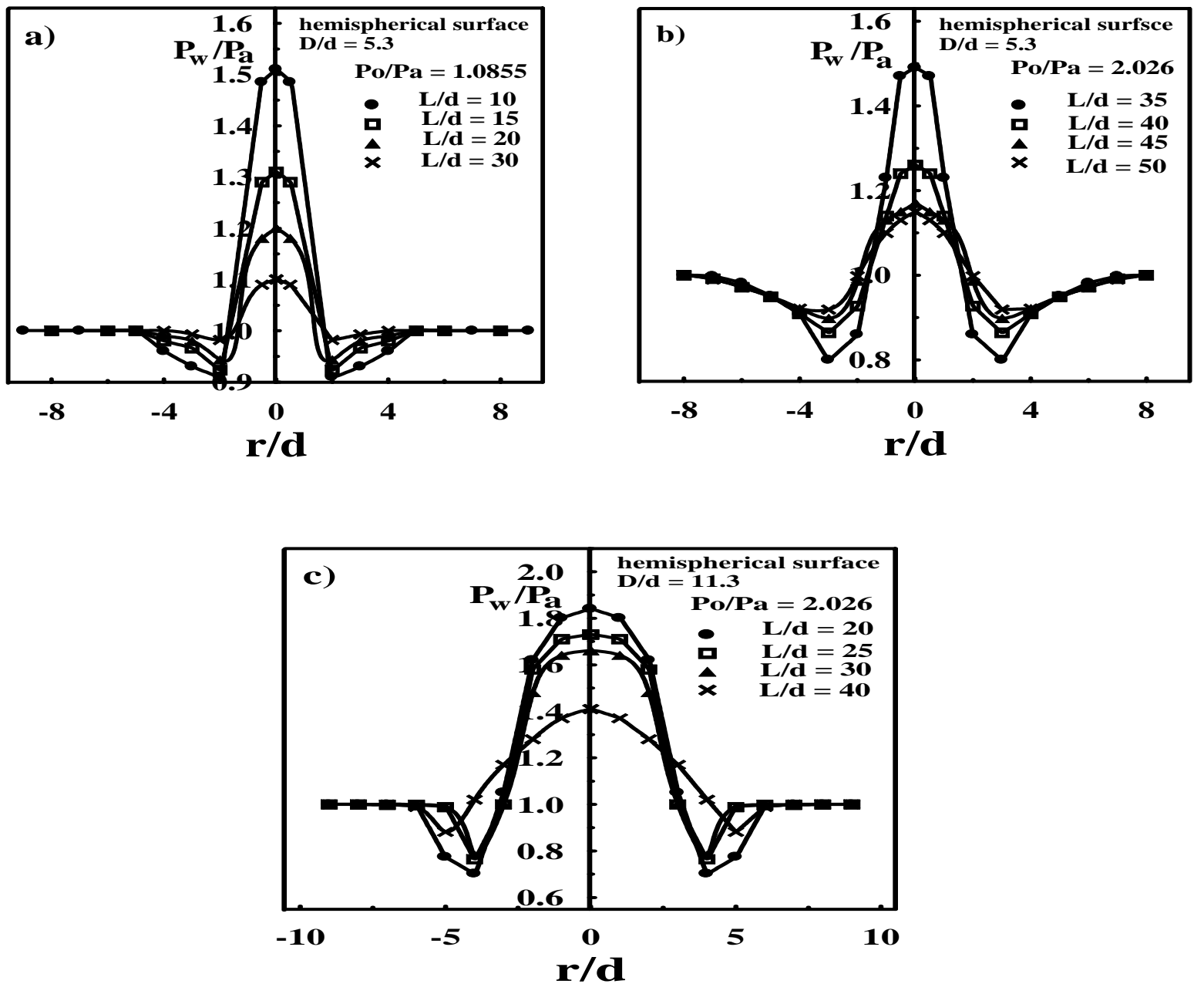

Fig. 6 Wall pressure distribution along the hemispherical surface
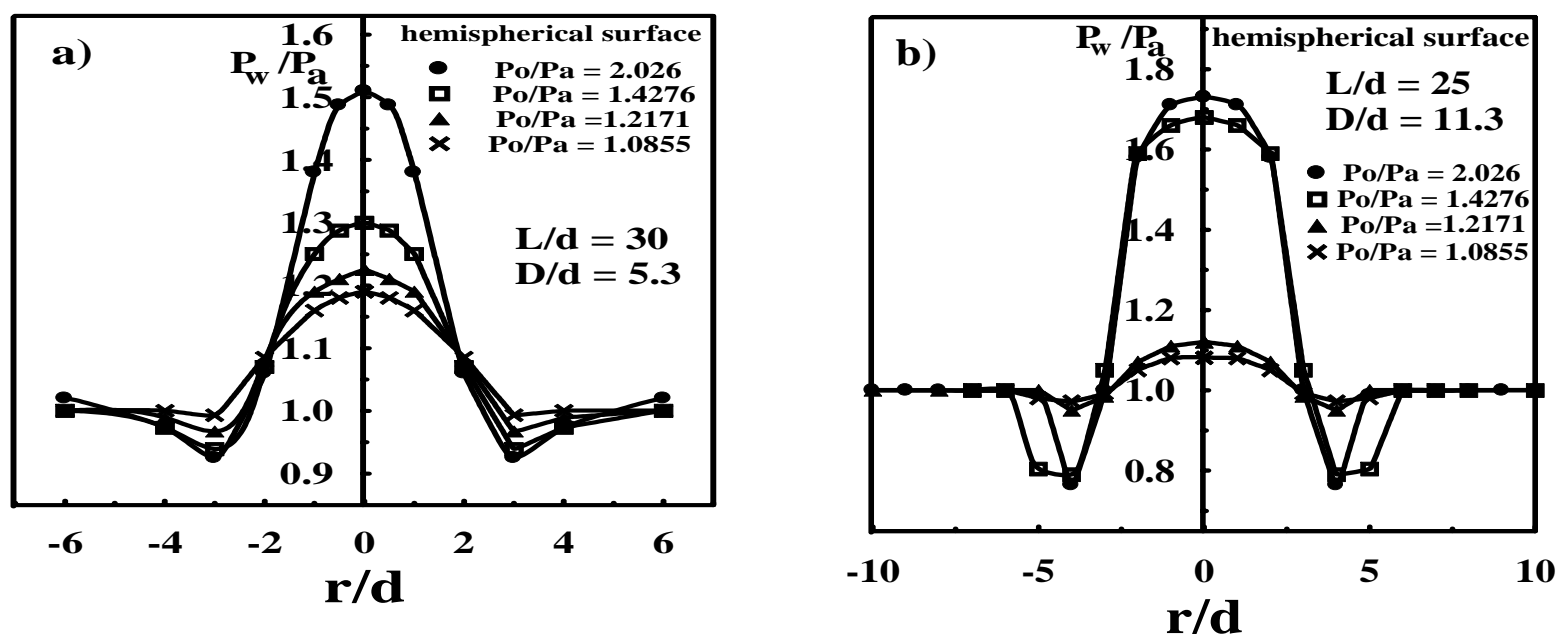

Fig. 7 Effect of stagnation pressure on Wall pressure distribution along the hemispheric surface 

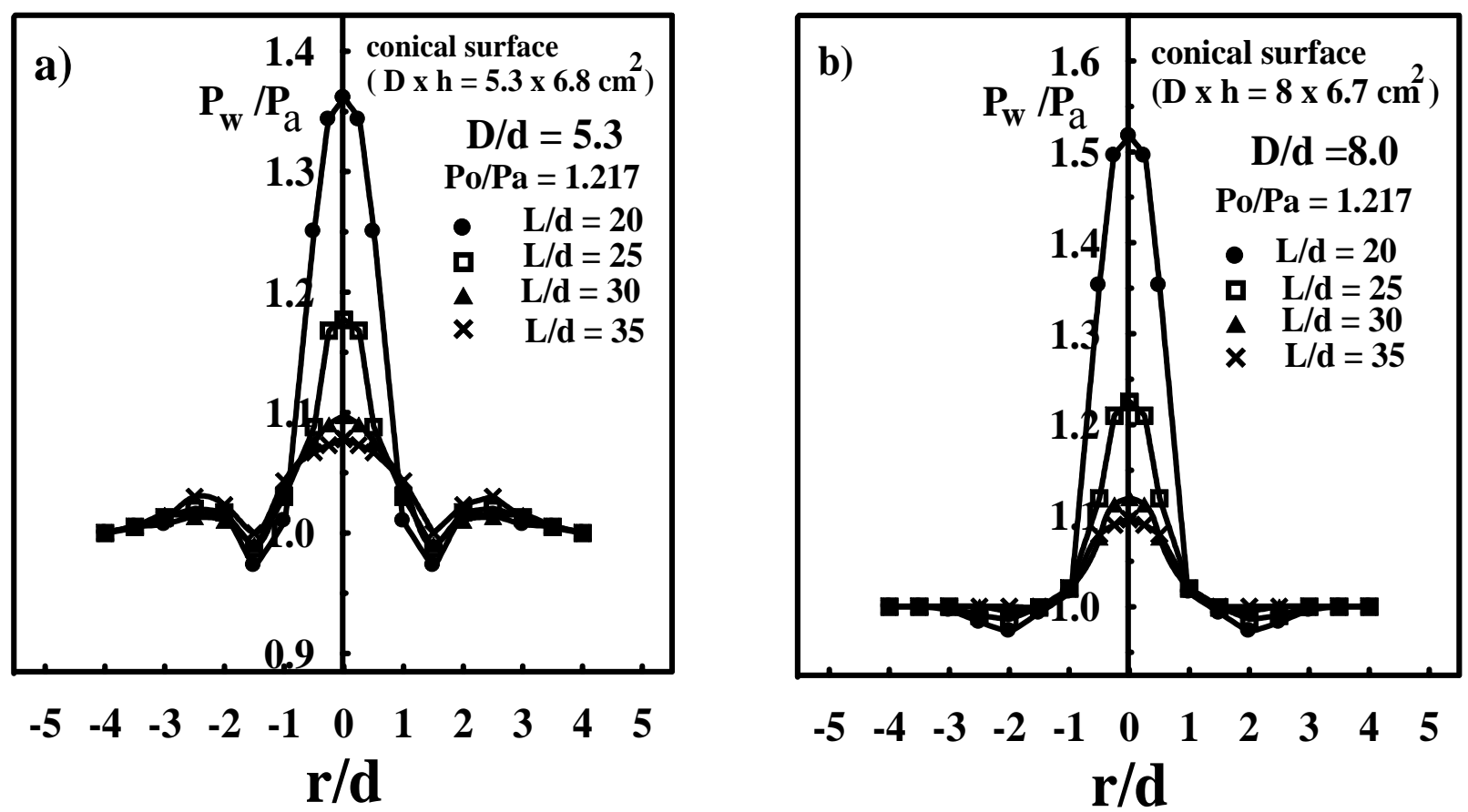

Fig. 8 Wall pressure distribution along a conical surface

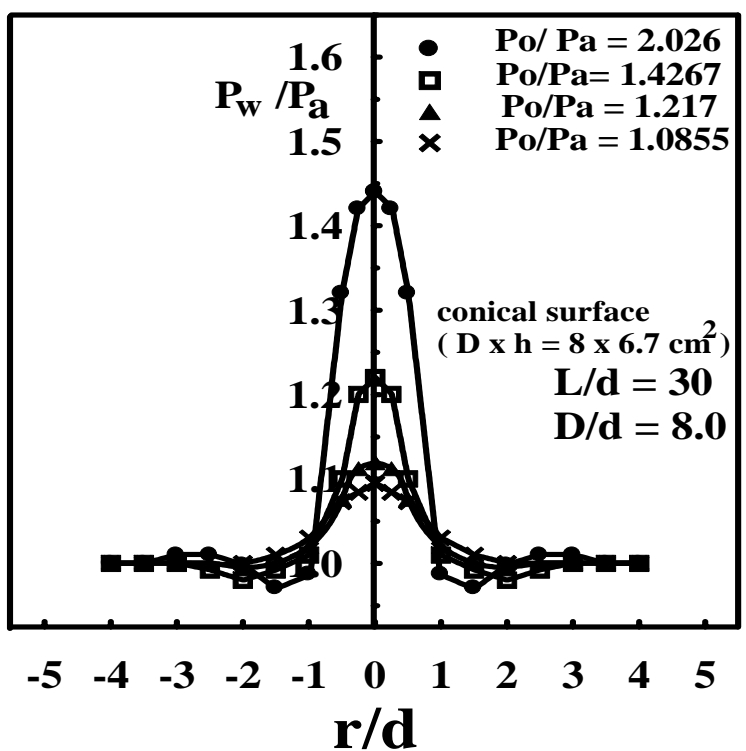

Fig. 9 Effect of stagnation pressure on Wall pressure distribution along a conical surface 
F.Sh. Abou-Taleb, A. Abdel-Fattah, and Gamal H. Moustafa, "Study Of Air Jet Impinging On Curved Surfaces"

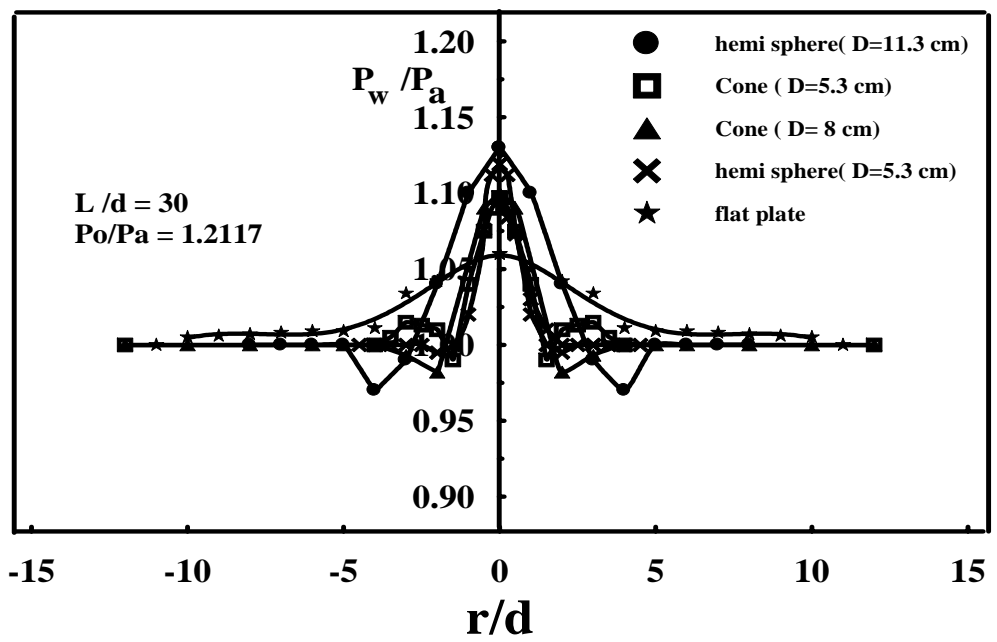

Fig. 10 Comparison between the tested surfaces.
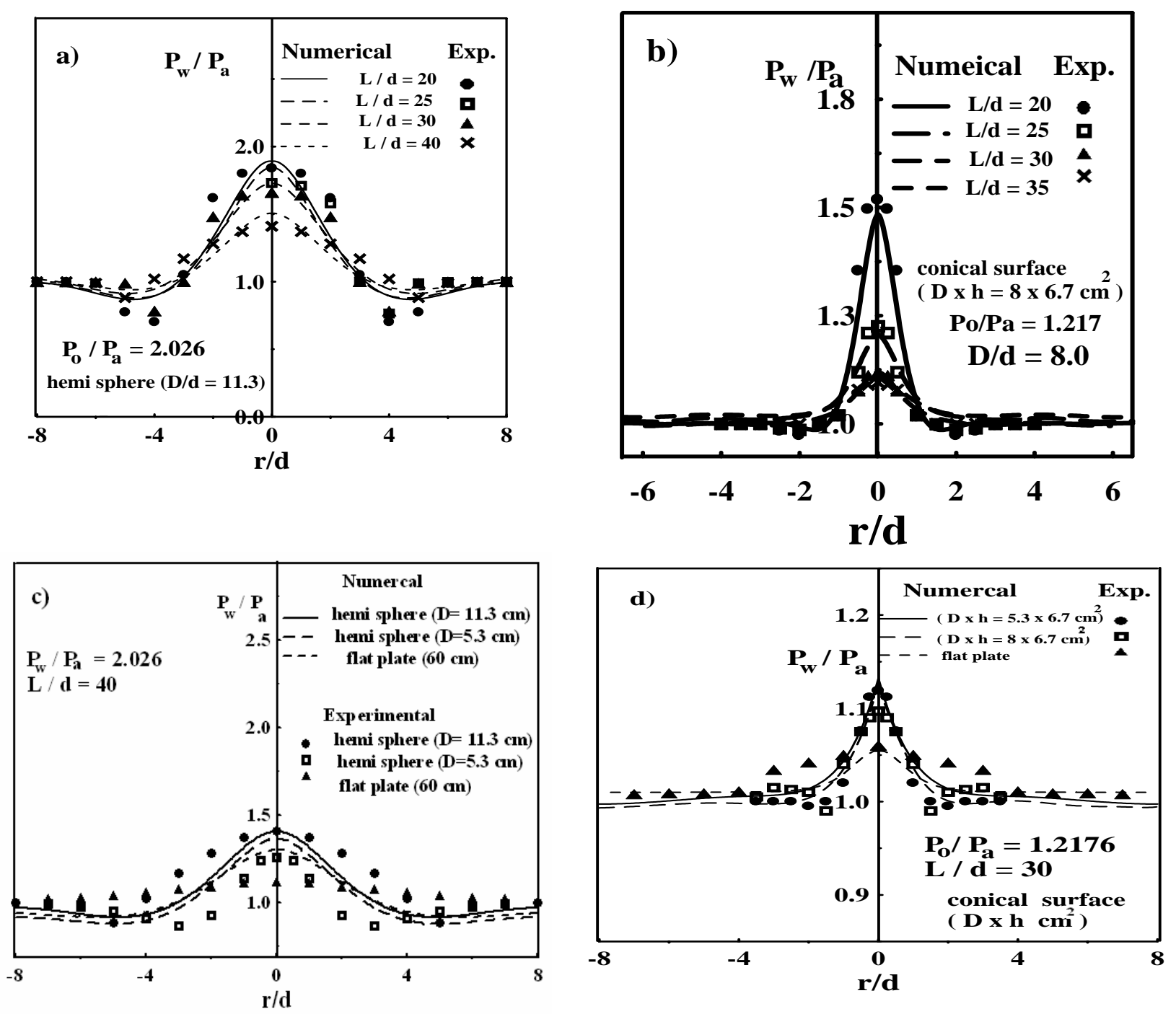

Fig. 11 Comparison between the theoretical and experimental results 
F.Sh. Abou-Taleb, A. Abdel-Fattah, and Gamal H. Moustafa, "Study Of Air Jet Impinging On Curved Surfaces"
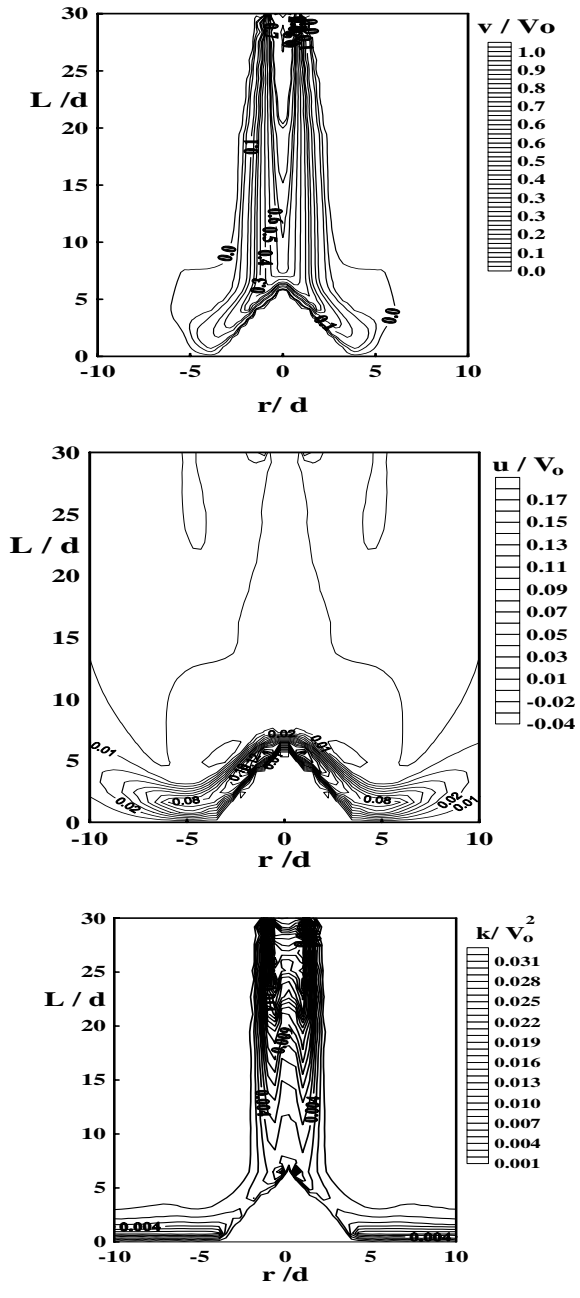

conical surface
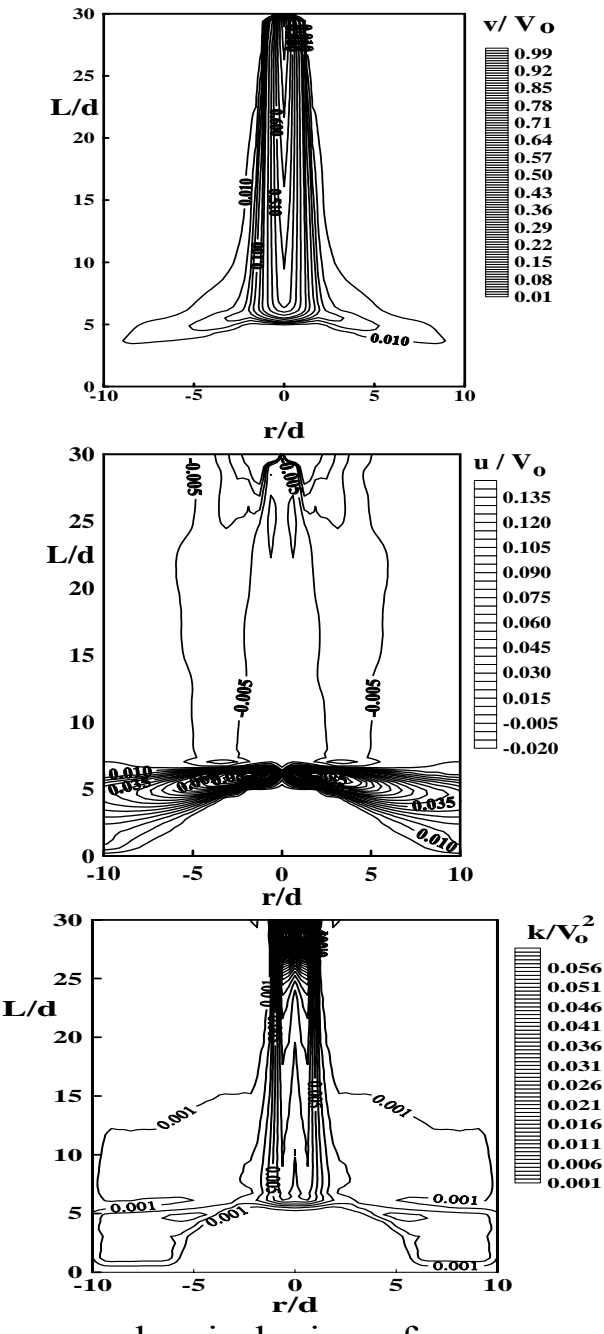

hemispheric surface

Fig. 12 contours of the velocities $v, u$ and kinetic energy $\mathrm{k}$ at $\mathrm{P}_{\mathrm{o}} / \mathrm{P}_{\mathrm{a}}=1.217$ and $\mathrm{L} / \mathrm{d}=30$ 